\title{
Modified high performance liquid chromatographic method for the identification of chlordiazepoxide in animal blood
}

\author{
Zena Sattam Hamad, Basil Mohammed Yahya \\ Department of Pharmacology, College of Pharmacy, University of Mosul, Mosul, Iraq.

$\frac{\text { Received }}{22.3 .2012} \quad \frac{\text { Accepted }}{30.4 .2012}$

\section{ABSTRACT}

Objective: A method for simultaneous determination of chlordiazepoxide in rat plasma using liquid-liquid extraction followed by high performance liquid chromatography (HPLC) is described.

Methods: The analytes were separated employing a LC-18 column $(250 \mathrm{~mm} \times 4.6 \mathrm{~mm}, 5 \mu \mathrm{m})$ at ambient temperature using methanol and water $(60: 40 \mathrm{v} / \mathrm{v})$ as a mobile phase at a flow rate $1.2 \mathrm{ml} / \mathrm{min}$. Ultra violet (UV) detection was carried out at $254 \mathrm{~nm}$. Employing liquid-liquid extraction (LLE), the best conditions were achieved with the extraction of $0.5 \mathrm{ml}$ plasma using $7.5 \mathrm{ml}$ deionized water, $0.5 \mathrm{ml}$ of $0.1 \mathrm{M} \mathrm{NaOH}$ and $2.5 \mathrm{ml}$ diethyl ether, the mixture was shaken for $15 \mathrm{~min}$, centrifuged, and an aliquot of the ether phase evaporated off in a water bath at $30^{\circ} \mathrm{C}$. The residue was reconstituted with the mobile phase $50 \mu 1$ followed by HPLC analysis.

Results and conclution: This method was validated for specificity and linearity with excellent correlation coefficient $(\mathrm{r}=0.99)$ showed their suitable applicability in order to examine chlordiazepoxide in rat plasma.

Key words: Chlordiazepoxide, chromatographic method, HPLC, rat plasma.

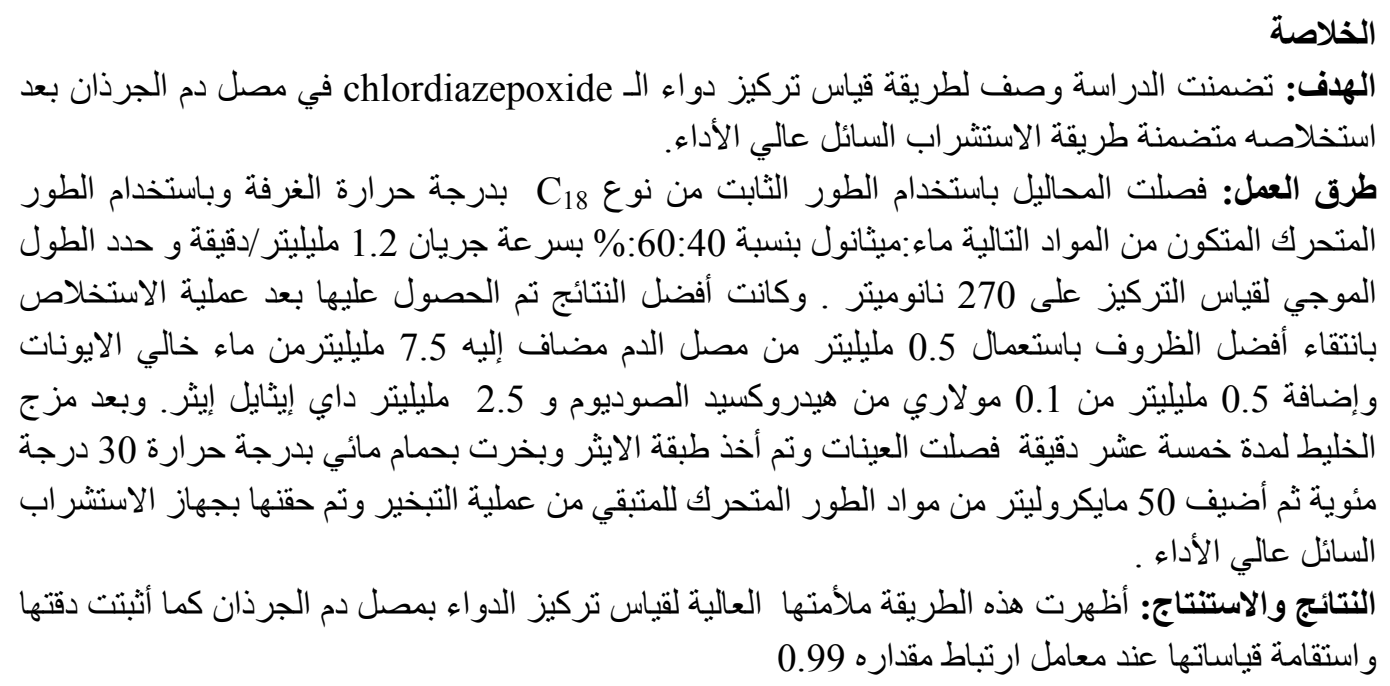

B enzodiazepines (BZPs) are an important class of drugs commonly used as minor tranquillizers, hypnotics and muscle relaxants ${ }^{1,2}$. They are among the most frequently prescribed drugs for the treatment of anxiety, sleep disturbance and status epilepticus ${ }^{3-5}$. In addition, BZPs are used to relieve tension in the 
preoperative period and to induce amnesia in surgical procedures ${ }^{6}$.

Chlordiazepoxide, the prototype for the benzodiazepine compounds, has important effects in treating a variety of medical disorders ${ }^{7}$. Thus, extraction and identification of chlordiazepoxide in biological fluids is very important for forensic and clinical toxicology ${ }^{8}$. Various researchers have reported total plasma concentrations of chlordiazepoxide in relation to both clinical effect and toxicity, indicating that the therapeutic monitoring of this drug is important, but non of the articles dealt with animal blood samples ${ }^{9}$.

Analytical methods include thinlayer chromatography, which tends to lack specificity, and gas chromatography, which often requires formation of derivatives for the determination of thermally labile chlordiazepoxide are not applicable for quantification. Hence, high-pressure liquid chromatography (HPLC) has become the most widely used analytical technique for the determination of chlordiazepoxide ${ }^{10}$.

Analytical test method validated in this work for animal blood sample is completed to ensure that it is accurate, precise, specific, sensitive, reproducible and robust over the specified range that an analyte will be analyzed. Also a specific method for identification and quantification of chlordiazepoxide in biological fluids is described.

Materials and methods

\section{Chemicals and Reagents}

Purified free base of chlordiazepoxide for research purposes was provided by Nenava Drug Industry (NDI), Iraq .

All solvents used were HPLC grade, and all chemicals were analytical grade: HPLC-grade methanol (Scharlau/Spain) and deionised water NDI/Iraq. Analytical grade sodium hydroxide and diethyl ether were from GCC company, UK.

\section{Instrumentation}

The analyses were carried out using a chromatographic system from Shimadzu Corporation (Japan). This instrument consisted of a pump, a UVvisible detector, a system controller, and a manual injector. Software was used to control the LC system and data acquisition.

The simultaneous analysis of chlordiazepoxide was performed at room temperature on a $\mathrm{C} 18$ column ( $4.6 \mathrm{~mm} \times 250 \mathrm{~mm}$ I.D., $5 \mu \mathrm{m}$ particle size) (GL Sciences Inc.) using methanol: water $(60: 40, \mathrm{v} / \mathrm{v})$ as mobile phase at a flow rate of $1.2 \mathrm{ml} / \mathrm{min}$. UV detector was operated at $254 \mathrm{~nm}$. The mobile phase was filtered through a millipore membrane filter $(0.45$ $\mu \mathrm{m})($ Steril-R, USA) and degassed ultrasonically prior to use.

Preparation of stock solution and working standards

Stock solution of chlordiazepoxide was freshly prepared in mobile phase solution at the concentration of $10 \mathrm{mg} / 10 \mathrm{ml}$. Working standards of chlordiazepoxide were freshly prepared in the concentrations of $0.125,0.25,0.5,1,2,4,8$ and $10 \mu \mathrm{g} / \mathrm{ml}$ and made by the dilution of the stock solution with mobile phase. 


\section{Animals and sample preparation}

Adult albino rats were used in this work that have been taken from animal house of the College of Veterinary Medicine, University of Mosul. This study was carried out on 5 animals (male and female), their weights were between 250-350 g. The work was done at laboratory of the College of Veterinary Medicine, University of Mosul.

One $\mathrm{ml}$ of blood samples were collected from healthy adult rats, not taking any kind of drug, in heparinized glass tubes, then one $\mathrm{ml}$ of blood samples were collected from each animal after 15, 30, $60 \mathrm{~min}$ of administration of therapeutic dose of chlordiazepoxide $(50 \mathrm{mg} / \mathrm{kg})$ was given by i.m. route to each animal ${ }^{9}$.

The blood samples were centrifuged at $3000 \mathrm{rpm}$ for $15 \mathrm{~min}$ and the plasma was frozen and stored at $20^{\circ} \mathrm{C}$, no longer than $72 \mathrm{~h}$.

\section{Extraction of the samples}

A liquid-liquid extraction (LLE) in which plasma $(0.5 \mathrm{ml})$ was mixed with, deionized water $(0.75 \mathrm{ml})$ and sodium hydroxide $0.1 \mathrm{M}(0.5 \mathrm{ml})$ in a stoppered test tube $(15 \mathrm{ml})$. The mixture was extracted with diethyl ether $(2.5 \mathrm{ml})$ by mechanically shaking for $15 \mathrm{~min}$. The resultant mixture was centrifuged, and an aliquot of the ether phase $(2 \mathrm{ml})$ transferred to a tapered test tube and the ether evaporated off in a water bath at $30{ }^{\circ} \mathrm{C}$. The residue was reconstituted with the mobile phase $(50 \mu l)$ used for the HPLC analysis. The test tube was vortex mixed and aliquots $(20 \mu \mathrm{l})$ were injected on to the column of instrument $^{11}$.

\section{Chromatographic conditions}

Several chromatographic conditions, such as mobile phase, type of column and its length, mobile phase flow rate, temperature and volume of injection were studied to obtain a satisfactory chromatographic separation (good resolution and efficacy) for the compound. In addition, the total time required for the analysis was also an important factor because the analysis could be unfeasible since interfering compounds could elute close to the chlordiazepoxide, modifications were performed in order to reduce the analysis time.

Various solvents or mixture of solvents at different compositions were used to extract the chlordiazepoxide from rat plasma.

To optimize the HPLC parameters, several mobile phase compositions were tried like:

1. $0.5 \mathrm{M}$ potassium dihydrogen phosphate $\quad\left(\mathrm{KH}_{2} \mathrm{PO}_{4}\right)$ : Methanol : Acetonitrile $(40: 40: 20)^{12}$.

2. Methanol : water $(60: 40)^{13}$.

The flow rate was adjusted at 0.8 $\mathrm{ml} / \mathrm{min}$ : chlordiazepoxide elute at $19.7 \mathrm{~min}$, then adjusted at $1 \mathrm{ml} / \mathrm{min}:$ it eluted at $15.8 \mathrm{~min}$, then finally adjusted at $1.2 \mathrm{ml} / \mathrm{min}$ : it eluted at $12.8 \mathrm{~min}$ at ambient temperature.

\section{Results}

A satisfactory separation and good peak symmetry was found in a mixture of methanol:water in the ratio of $60: 40 \%, \mathrm{v} / \mathrm{v}$ at a flow rate of $1.2 \mathrm{ml} / \mathrm{min}$. The optimum wavelength for detection was set at $254 \mathrm{~nm}$ at which much better detector response for drug was obtained. The retention 
time was $12.8 \quad \mathrm{~min}$ for peak area. Better resolution of the chlordiazepoxide and no interferences peaks with clear base line separation is were observed in formulation sample, also with a better reproducibility. found as shown in Table 1, Figure 1 and 2 .

Quantification was achieved with UV detection at $254 \mathrm{~nm}$ based on the

Table 1. Optimized chromatographic conditions for estimation of chlordiazepoxide

\begin{tabular}{|c|l|}
\hline Mobile phase & Methanol : water $60: 40 \%, \mathrm{v} / \mathrm{v}$ \\
\hline Pump mode & Isocratic \\
\hline Diluent & Mobile phase \\
\hline Column & C18 column $(4.6 \times 250 \mathrm{~mm}, 5 \mu \mathrm{m})$ \\
\hline Column temp. & Ambient \\
\hline Wavelength & $254 \mathrm{~nm}$ \\
\hline Injection volume & $20 \mu \mathrm{l}$ \\
\hline Flow rate & $1.2 \mathrm{ml} / \mathrm{min}$ \\
\hline Run time & $15 \mathrm{~min}$ \\
\hline Retention time & $12.8 \mathrm{~min}$ \\
\hline &
\end{tabular}

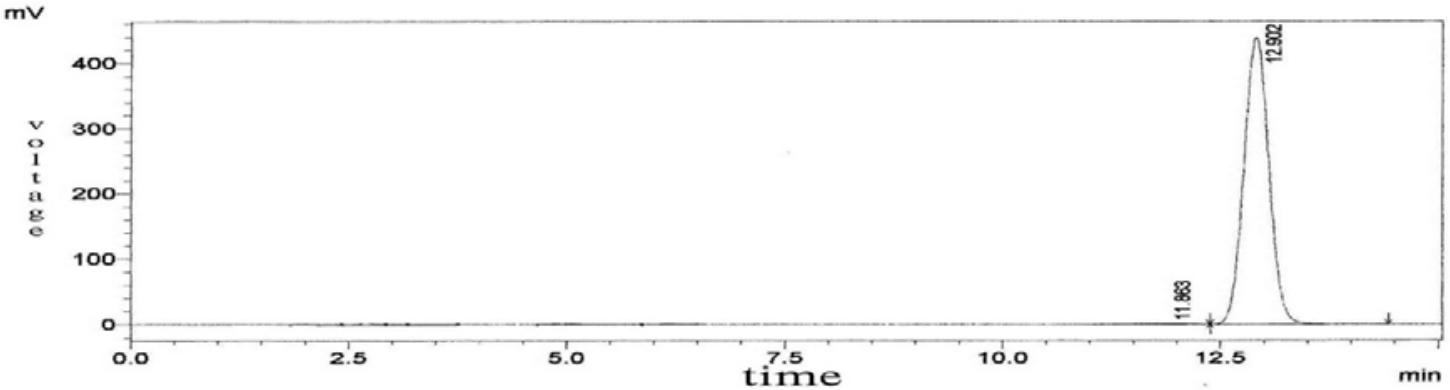

Figure 1. Chromatograms of validation of the method for chlordiazepoxide 


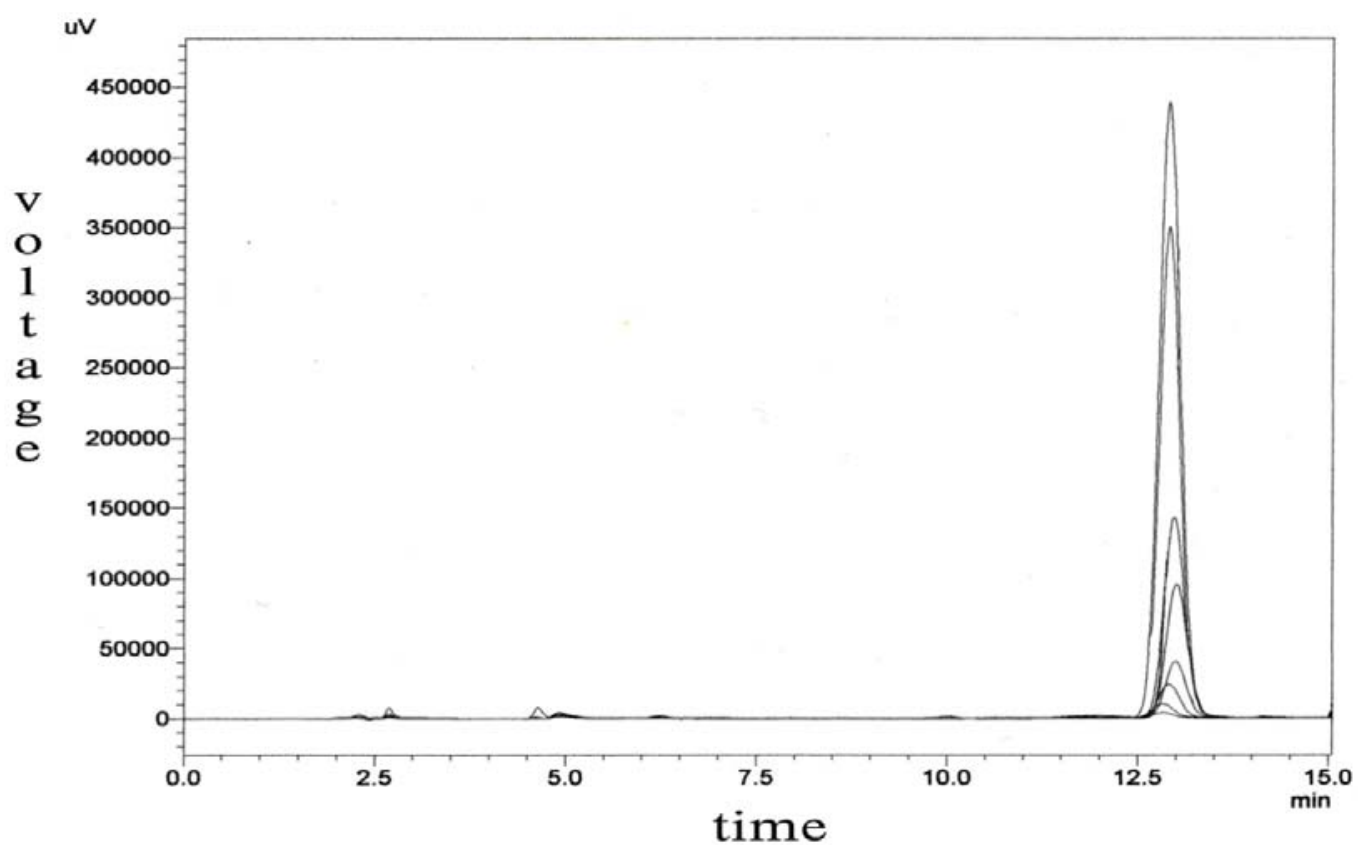

Figure 2. Chromatograms of standards solutions with different concentrations of chlordiazepoxide

\section{Specificity}

The specificity of method was performed by comparing the chromatograms of blank, standard and sample. It was found that there is no endogenous interference and also found good correlation between the retention times of standard and sample are shown in Table 2, Figure 3,4 and 5.

Table 2. Specificity study (Retention time of blank, standard and sample)

\begin{tabular}{|c|c|}
\hline Name of the solution & Retention time in Min (Rt) \\
\hline Blank & No peak \\
\hline Standard & 12.8 \\
\hline Sample & 12.8 \\
\hline
\end{tabular}




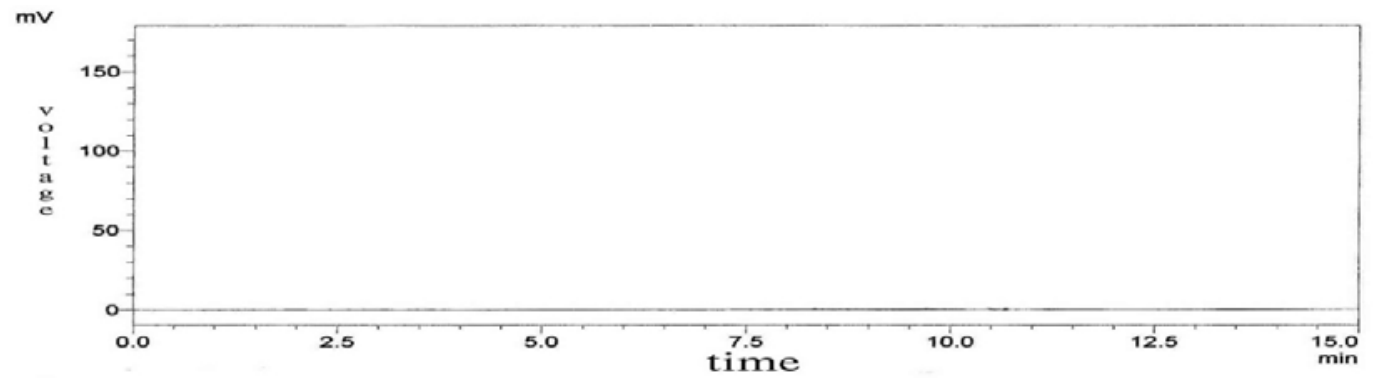

Figure 3. Chromatogram of blank

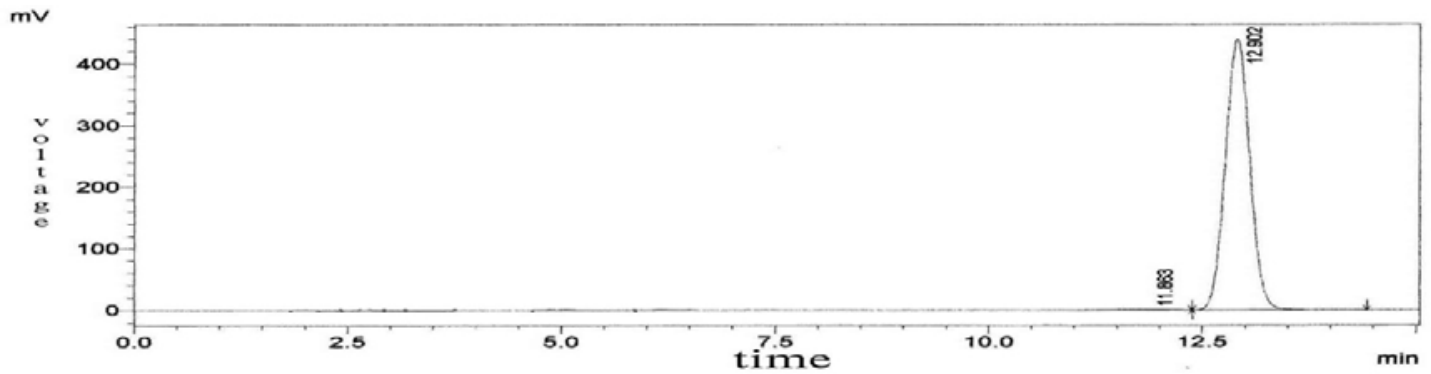

Figure 4. Chromatogram of standard chlordiazepoxide

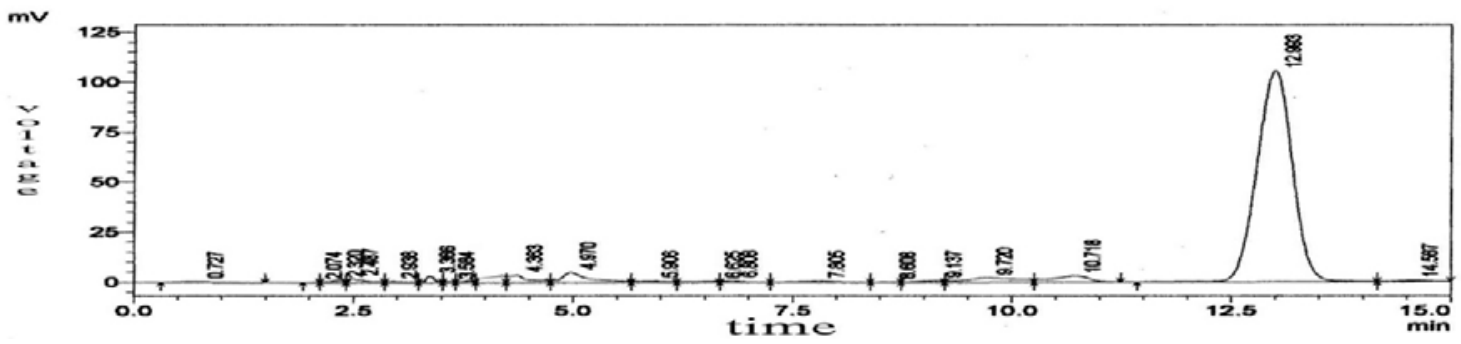

Figure 5. Chromatogram of sample

\section{Linearity}

Linearity was performed by preparing standard solutions of chlordiazepoxide at different concentration levels including working concentration mentioned above. Twenty microliters of each concentration was injected in duplicate into the HPLC system. The response was read at $254 \mathrm{~nm}$ and the corresponding chromatograms were recorded. From these chromatograms, the mean peak areas were calculated and linearity plot of concentrations over the mean peak areas were constructed. The regression of the plot was computed by least square regression method. Linearity results were presented in Table 3, calibration plot was shown in Figure 6 and calibration plots of the samples was shown in Figure 7. 
Table 3. Linearity Results

\begin{tabular}{|c|c|c|}
\hline Levels & $\begin{array}{c}\text { Concentration of } \\
\text { chlordiazepoxide in }(\mu \mathrm{g} / \mathrm{ml})\end{array}$ & Mean peak area $(\mathrm{mV})$ \\
\hline 1 & 0.125 & 91570.4 \\
\hline 2 & 0.25 & 173699.1 \\
\hline 3 & 0.5 & 469904.1 \\
\hline 4 & 1 & 847053.6 \\
\hline 5 & 2 & 2032980 \\
\hline 6 & 4 & 2883865 \\
\hline 7 & 8 & 7221231 \\
\hline 8 & 10 & 8674700 \\
\hline Range: 0.125 & Slope & 873892.8 \\
to 10 & Intercept & -27121.7 \\
& Correlation coefficient & 0.9935 \\
& & \\
\hline
\end{tabular}

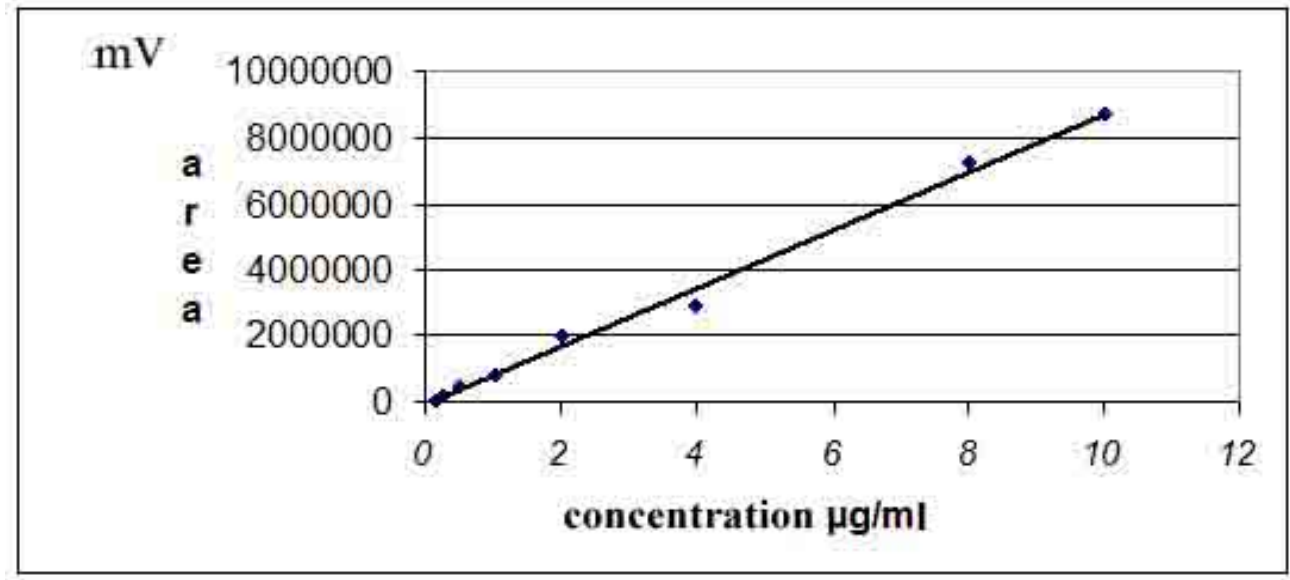

Figure 6. Calibration plot for chlordiazepoxide standards on $\mathrm{X}$ axis concentration $(\mu \mathrm{g} / \mathrm{ml})$ and on $\mathrm{Y}$ axis peak area $(\mathrm{mV})$ 

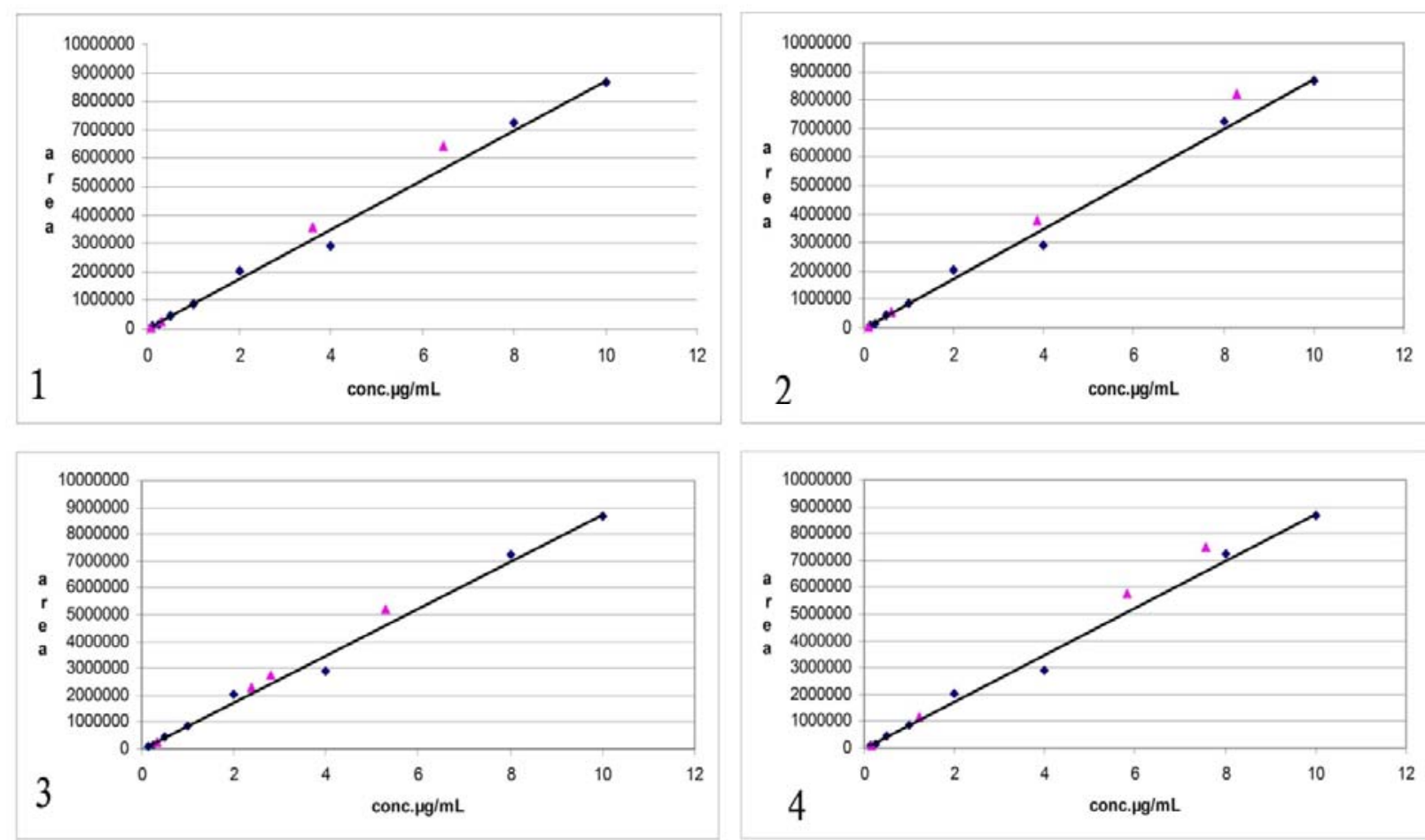

\section{$\Delta$ concentration of samples \\ concentration of standards}

\section{$(1,2,3,4,5)$ the number of animal used}

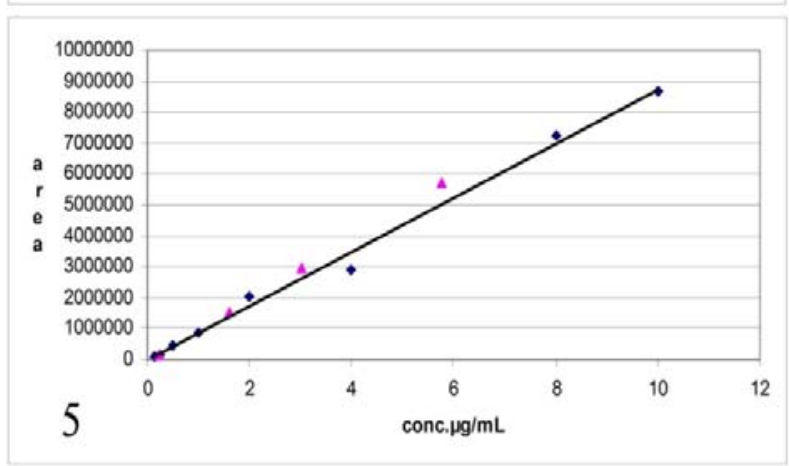

Figure 7. Calibration plots for chlordiazepoxide plasma concentration-area at $(0,15,30,60 \mathrm{~min})$ after i.m. administration of the drug in 5 animals

- Calibration curves were found to be linear with correlation coefficient (0.9935), and the intercept and the slope values were found to be (-60500) and (1000000) respectively. 


\section{Discussion}

HPLC combines many of the advantages of other methods by providing adequate separation of components at room temperature with quantification of the $\operatorname{drug}^{11}$. While analytical methods include thin-layer chromatography, tend to lack specificity, and gas chromatography, often requires formation of derivatives for the determination of thermally labile chlordiazepoxide ${ }^{10}$.

HPLC method provides an assurance of reliability during normal use, and is sometime referred to as the process of providing documented evidence that the method dose what it is intended to do ${ }^{14}$.

Chlordiazepoxide analysis in rat plasma by HPLC presents high detectability to allow detection of low quantities of analytes $(\mu \mathrm{g} / \mathrm{ml})$. HPLC with UV detection employing LiquidLiquid Extraction conforms the employment of the technique in routine analysis.

The quantitative evaluation was carried out in rat plasma using chlordiazepoxide, the results showed that the data were accurate for all the 5 animals within the acceptance level of the standard concentrations at the quantitation limit.

Modification of a procedure described above gave good elution of the drug Figure 1.

Extraction procedure usually resulted in an extract which was free from interfering peaks Figure 5. Since the peaks were fairly symmetrical and peak areas were used as a measure of concentration.

Several papers have been described in the literature for the simplicity of analysis of benzodiazepaine from biological fluids by HPLC, Pongraveevongsa, et. al. ${ }^{8}$ determine BZPs in human serum by HPLC with solid phase extraction. Skellern et al. ${ }^{15}$ describe the application of HPLC in determination of some BZPs and their metabolites in human plasma. Borges, et. al. ${ }^{1}$ investigate liquid-liquid extraction and solid-liquid extraction for determination of BZPs in human plasma by HPLC/UV, and Mergen, et. $\mathrm{Al}^{2}$ described a therapeutic drug monitoring of BZPs in human plasma and urine by HPLC.

The primary concern of this study was the simplicity of the method to be used in clinics or hospitals for both humans and animals. Therefore, rather than the method itself, this study stands out for its clinical application. This study showed that the dosage of medication should be adjusted carefully according to the analytical data relating to drug levels in plasma for each individual animal.

\section{Reference}

1. Borges KB, Freire EF, Martins I, et al. Simultaneous determination of multibenzodiazepines by HPLC/UV: Investigation of liquidliquid and solid-phase extractions in human plasma. Talan 2009;78:233-41.

2. Mergen G, Söylemezoğlu T, Ilhan I. et al. Theraputic diazepam monitoring in human plasma and urine by HPLC: an application for alcoholism. Chromatography online. 2009.

3. Martin J L, Sainz-Pardo M, Furukawa TA, et al. Benzodiazepines in generalized 
anxiety disorder: heterogeneity of outcomes based on a systematic review and meta-analysis of clinical trials. J Psychopharmacol 2007;21(7):774-82.

4. Olkkola KT, Ahonen J. Midazolam and other benzodiazepines. Handb Exp Pharmacol 2008;182:335-60.

5. Dikeos DG, Theleritis CG, Soldatos CR. Benzodiazepines: effects on sleep. In Pandi-Perumal SR, Verster JC, Monti JM, Lader M, Langer SZ editors. Sleep Disorders: Diagnosis and Therapeutics. Informa Healthcare; 2008 pp. 220-2.

6. Broscheit J, Kranke P. The preoperative medication: background and specific indications for the selection of the drugs. Anasthesiol Intensivmed Notfallmed Schmerzther 2008;43(2):134-43.

7. Cooper JR, Bloom FE, Roth RH. The Complete Story of the Benzodiazepines $7^{\text {th }}$ edition. USA: Oxford University Press 1996 pp.3

8. Pongraveevongsa $\mathrm{P}$, Vichairat $\mathrm{K}$, Sribanditmongkol P, Khobjai W. Determination of benzodiazepines in serum by The high-performance liquid chromatographic Method with solid phase extraction. Chiang Mai Med J 2007;46(1):23-30.

9. Nissen D. Mosby's Drug Consult. Missouri USA:Mosby,Inc.2002. http://www.mosbysdrugconsult.com 10. Moore CM, Sato K, Katsumata Y. Rapid monitoring of benzodiazepines in clinical samples by using on-line column switching HPLC. Clin Chem 1991;37(6):8048.

11. Skellern GG, Meier J, Knight BI, Whiting B. The application of HPLC to the determination of some 1,4 benzodiazepines and their metabolites in plasma. $\mathrm{Br} \mathrm{J}$ Clin Pharmac 1978;5:483-487.

12. Water corporation, Symmetry columins, Application Note book; 2003 p.53-54.

13. The United State Pharmacopoia Convection, Inc, 30 NF25, 2007.

14. Choudhury T, Ghosh A, Deb J. Reverse phase HPLC method and method validation of diazepam by single mobile phase. Int $\mathrm{J}$ Pharm Sci Biol 2010;1(1):7-12.

15. Skellern GG, Meier J, Knight BI, Whiting B. The application of HPLC to the determination of some 1,4 benzodiazepines and their metabolites in plasma. $\mathrm{Br} \mathrm{J} \mathrm{Clin}$ Pharmacol. 1978;5(6):483-7. 